\title{
HOMERO BRASILEIRO: ODORICO MENDES TRADUZ A ÉPICA CLÁSSICA
}

\author{
José Quintão de Oliveira* \\ Universidade Federal de Minas Gerais
}

\begin{abstract}
Manuel Odorico Mendes wrote a few verses from his own craft wich survived and reached the present time as À tarde (To the Evening), but got his place on Literary Companions as a translator, converting into the Portuguese language the Classical Epic (The Iliad, The Odissey, The Aeneid) and other works including a modern writer (Voltaire). His effort was well received for some of his contemporaries as João Francisco Lisboa, but later encountered a strong oposition from critics as Silvio Romero, and after him Antonio Candido. Recently some critics atained to the Concret Poetry and others try to recover Odorico translating works, sometimes confering him distinguished offspring as Sousândrade and Guimarães Rosa. This paper intents to analyse Odorico poetry as well as what say his critics aiming to contribute to verify his place on the Brazilian Classical Poetry and consequently on the Literature itself.

KEYWORDS: Literary criticism; classical literature; Brazilian literature; translation; Odorico Mendes.
\end{abstract}

\section{Introdução}

quela que é talvez a mais conhecida e discutida versão da Ilíada em língua portuguesa começa pelos versos por demais conhecidos:

Canta-me, ó deusa, do Peleio Aquiles ${ }^{1}$

A ira tenaz, que, lutuosa aos Gregos,

^jqojqo@yahoo.com.br

${ }^{1}$ Atualizou-se a ortografia, preservando-se a pontuação e as iniciais maiúsculas originais. 
Verdes no Orco lançou mil fortes almas,

Corpos de heróis a cães e abutres pasto:

Lei foi de Jove, em rixa ao discordarem

O de homens chefe e o Mirmidon divino.

Nume há que os malquistasse? o que o Supremo

Teve em Latona. Infenso um letal morbo

No campo ateia; o povo perecia,

Só porque o rei desacatara a Crises.

Com ricos dons remir viera a filha

Aos alados baixéis, nas mãos o cetro

E a do certeiro Apolo ínfula sacra.

Ora e aos irmãos potentes mais se humilha:

"Atridas, vós aqueus de fina greva,

Raso o muro Priâmeo, assim regresso

Vos dêem feliz do Olimpo os moradores!

Peço a minha Criseida, eis seu resgate;

Reverentes à prole do Tonante,

Ao Longe-vibrador, soltai-me a filha".

Manuel Odorico Mendes, também por demais conhecido criador desses versos, escreveu alguns poemas de estro próprio, como o "À tarde", 3 mas garantiu sua entrada nos compêndios literários mesmo como tradutor, tendo vertido ao português a épica clássica - Eneida e Odisseia, além da Ilíada - traduziu ainda as Bucólicas e as Geórgicas e também um escritor mais próximo, Voltaire. Seu trabalho foi à época valorizado por alguns confrades como João Francisco Lisboa, Henrique Alves de Carvalho e Antônio Henriques Leal, mas veio a encontrar forte resistência em leitores como Sílvio Romero. O mesmo caminho foi trilhado por Antonio Candido na sua Formação da literatura brasileira, destacando-lhe as limitações de gosto e o pouco engenho poético. Mais recentemente, alguns críticos - especialmente os concretistas - tentam recuperar o empreendimento tradutório odoricano, atribuindo-lhe, inclusive, ilustre descendência: Souzândrade e Guimarães Rosa, por

\footnotetext{
${ }^{2}$ Ilíada, I, 1-20 (1874).

${ }^{3}$ Wolf [Le Brésil littéraire. Histoire de la littérature brésilienne suivie d'un choix de morceaux tirés des meilleurs auteurs brésiliens. Berlin: A. Asher \& Co. (Albert Cohn \& D. Collin), 1863] e Leal (Manuel Odorico Mendes. In: . Pantheon maranhense. Ensaios biográficos dos maranhenses ilustres já falecidos. Lisboa: Imprensa Nacional, 1873-1875. Vol. I, 1873. p. 1-99) reproduzem esse poema como "Hino à tarde", porém, o melhor título parece ser "À tarde", que é como aparece na Minerva, a que certamente foi encaminhado pelo autor, que ali publicou também inéditos das suas traduções.
} 
exemplo. O texto que se segue propõe-se a analisar, ainda que sumariamente, o trabalho deste tradutor, bem como a cotejar-lhe a fortuna crítica - melhor dizer suma, tão poucos têm sido os críticos a tornar pública sua leitura -, na tentativa de verificar o lugar do ilustrado maranhense nas letras clássicas e, consequentemente, na literatura brasileira em geral.

\section{O poeta que Sílvio Romero elogiou}

Manuel Odorico Mendes nasceu em São Luís, no Maranhão, em 1799 e morreu, durante uma viagem de trem, próximo a Londres, Inglaterra, em 1864. É figura de proa como político ativo nos conturbados anos 30 e 40 do século 19; secundariamente a essa figura, existiram o poeta e o erudito. O hino "À tarde", que segundo Wolf foi escrito quando o autor era ainda estudante em Coimbra, ${ }^{4}$ teve admiradores importantes e foi dos poucos versos de lavra própria publicados ainda em vida do tradutor de Homero e Virgílio:

Tarde serena e pura, que lembranças

Não nos vens despertar no seio d'alma?

Amiga tenra, dize-me, onde colhes

O bálsamo que esparges nas feridas

Do coração? que, apenas dás rebate

Cala-se a dor; só geras no imo peito

Mansa melancolia, qual ressumbra

Em quem sob os seus pés tem visto as flores

Irem murchando, e a treva do infortúnio

Pouco a pouco ante os olhos condensar-se. ${ }^{5}$

Sílvio Romero diz desse poema que "nunca o pude ler sem boa e saudosa emoção". [E que nele] "circula um não sei quê de vago e doce, que bem parece a essência mesma da poesia”. ${ }^{6}$ Para José Veríssimo, "mesclam-se nesta composição o clássico e o romântico, uma inspiração ainda arcádica e europeia e sentimentos brasileiros e estilo moderno".

\footnotetext{
${ }^{4}$ Cf. Wolf, op. cit., vol. I (existe versão brasileira: Brasil literário. Tradução, prefácio e notas de Jamil Almansur Haddad. São Paulo: Nacional, 1955).

${ }^{5}$ Cf. Mendes apud Lisboa (Biographia do autor escripta e publicada em 1862 por João Francisco Lisboa. In: Homero. Ilíada. Rio de Janeiro: Typographia Guttemberg,1874, p. XXII).

${ }^{6}$ Cf. Romero, S. História da literatura brasileira. Rio de Janeiro: José Olympio, 1949, p. 32.
} 
Para este crítico, o poema de Odorico é do que de melhor se produziu no seu tempo e - "prenuncia Gonçalves Dias pelo tom sentimental do seu lirismo mais subjetivo que o de [Gonçalves de] Magalhães". ${ }^{7}$ Palavras generosas, porém bastante sensatas, considerando-se que sua primeira publicação em opúsculo pelo impressor Ignacio Pereira da Costa ocorreu em 1832, tendo sido escrito mais de oito anos antes dessa data, como informa Antônio Henriques Leal. ${ }^{8}$ Romero e Veríssimo têm assim toda razão em valorizá-lo, comparado à produção literária de então, bastando lembrar que os Suspiros poéticos e saudades, de Gonçalves de Magalhães, só apareceriam em 1836 e Gonçalves Dias só estrearia em livro, com seus Primeiros cantos, em 1847. Assim, o poema tem um deserto literário a preencher e o faz com algum garbo. Isso, é importante anotar, por si só faz do seu autor figura importantíssima da nossa história literária.

Além desse "À tarde", Odorico Mendes publicou também um poema intitulado "O sonho" (ou "A morte", como consta em uma edição), incluído em diversas antologias, -

Quão triste a final cena!

Mas o quadro da vida inda é mais triste.

As breves alegrias

Num só ponto aparecem mais distintas,

E sombreiam-lhe o fundo e os infortúnios.

Que bens há cá na terra?

O crime estende o formidável cetro,

Raro fulge a virtude;

Em torno ao coração o prazer voa,

A dor penetra e vai sentar-se no âmago. ${ }^{9}$

- Antônio Henriques Leal registra este poema como tendo circulado nas páginas da Minerva Brasiliense. Talvez haja equívoco nessa informação, parece que o único poema de Odorico que ali apareceu foi o já referido "À tarde", ${ }^{10}$ como se pode confirmar nos índices da Minerva publicados por Hélio Lopes. ${ }^{11}$ Há notícias de poucos poemas da lavra de Odorico,

\footnotetext{
${ }^{7}$ Cf. Veríssimo, J. História da literatura brasileira. Brasília: UNB, 1963, p. 189.

${ }^{8}$ Cf. Leal, op. cit.

${ }^{9}$ Cf. Mendes apud Lisboa, op. cit., p. XXII.

${ }^{10}$ Cf. Minerva Brasiliense. Rio de Janeiro, vol. I, n. 12, p. 367-368, 15 de abril de 1844.

${ }^{11}$ Cf. Lopes, H. A divisão das águas. São Paulo: Conselho Estadual de Artes e Ciências Humanas, 1978, p. 269.
} 
quase todos recolhidos por Henriques Leal às páginas do Pantheon Maranhense. ${ }^{12}$ Esse livro dedica 99 páginas a uma biografia do escritor incluindo alguns poemas seus, praticamente todos de circunstância; uma nota de rodapé remete a um apêndice contendo outros três, os referidos "À tarde", "O sonho" e "Meu retiro". ${ }^{13}$ Além dessa parca produção, João Francisco Lisboa e Henriques Leal falam de um bauzinho que teria sido roubado ao autor durante uma viagem, em território da Bahia, e que conteria toda a produção inédita do poeta. Não recuperado o objeto, Odorico parece ter renunciado ao poetar autônomo para dedicar-se à tradução dos grandes.

\section{Da tradução de Odorico Mendes: breve nota histórica}

No número 3 da revista Minerva Brasiliense, datado de dezembro de 1843, circulou um fragmento da "Eneida portuguesa de Manuel Odorico Mendes, ou nova tradução da epopeia de Virgilio Publio Maro. Livro I" com o alerta "(continuar-se-á)", e, de fato, no número seguinte da revista, ${ }^{14}$ volta Odorico a ocupar quatro páginas com a sua tradução virgiliana. O tradutor publicou sua versão completa da Eneida em 1854; reeditando-a em 1858, juntou-lhe as Geórgicas e as Bucólicas sob o título geral de Virgílio brasileiro. Só depois disso, concluído o ciclo das traduções do latim, empreendeu a tradução de Homero. No início de 1863 concluiu sua versão da Ilíada e em julho do ano seguinte, um mês antes de morrer, encerrou o trabalho com a Odisseia.

A Ilíada foi publicada dez anos depois da morte do tradutor, como se informa na portada da primeira edição: "Ilíada de Homero em verso portuguez por Manoel Odorico Mendes da cidade de S. Luiz do Maranhão. Edictor e revisor, Henrique Alves de Carvalho também natural do Maranhão. Rio de Janeiro Typographia Guttemberg, Praça da Constituição n. 47. 1874”. Essa edição, feita com subsídio financeiro

${ }^{12}$ Cf. Leal, op. cit., p. 1-99.

${ }^{13}$ Cf. Leal, op. cit., p. 277-287.

14 "Eneida" portuguesa de Manuel Odorico Mendes, ou nova tradução da epopéia de Virgilio Publio Maro. Livro I (continuar-se-á). Minerva Brasiliense. Jornal de Ciências, Letras e Artes publicado por uma Associação de Literatos. Rio de Janeiro, vol. I, n. 3, p. 86-89, 1 de dezembro de 1843; "Eneida" portuguesa de Manuel Odorico Mendes, ou nova tradução da epopéia de Virgilio Publio Maro. Livro I (continuação do número antecedente). Vol. I, n. 4, p. 103-106, 15 de dezembro de 1843. 
do tesouro da então Província do Maranhão, contou também com o concurso indireto de outro maranhense ilustre, João Francisco Lisboa, que teve nela incluída uma biografia de Manuel Odorico que fizera publicar na Europa dois anos antes. ${ }^{15}$

Juntamente com a Ilíada estava também projetada uma edição da Odisseia, o que no entanto não ocorreu devido talvez à exiguidade da contribuição do governo da província natal do tradutor. De certo há que os originais permaneceram desaparecidos até 1913, quando um seu descendente entregou-os a um político maranhense que os repassou à Biblioteca Pública de São Luís, dali saindo em 1925 para serem editados pela Academia Brasileira de Letras, o que também não ocorreu, como anota o prefaciador. Finalmente chegaram ao público através da Livraria Freitas Bastos, do Rio de Janeiro, em 1928, com prefácio de Humberto de Campos, sempre às expensas do Erário da província, ora já Estado da República. A partir de 1992 teve edição acadêmica organizada por Medina Rodrigues, sob a direção geral de João Alexandre Barbosa, pela editora da Universidade de São Paulo.

\section{Suma crítica}

Sílvio Romero, que se encantou com o hino "À tarde", apresentou forte resistência à tradução de Odorico Mendes. "Ali tudo é falso, contrafeito, extravagante, impossível. São verdadeiras monstruosidades" ${ }^{16}$ Segundo o crítico - numa proposição carregada de acuidade - o trabalho de tradução requer três campos de conhecimento a serem considerados: culturais, relativos à história, mitologia, filologia etc; linguístico e artístico, isto é, poético. "O primeiro aspecto do problema foi pouco da alçada de Odorico; o segundo ele o conheceu; o terceiro faltou-lhe completamente". ${ }^{17}$

Com o eminente sergipano não concordou Martins Aguiar, leitor bastante entusiasmado do tradutor maranhense. Aguiar, professor de gramática no Ceará, reconhece em Odorico “um notável filólogo, mas,

\footnotetext{
${ }^{15}$ Cf. Lisboa, J. F. Manuel Odorico Mendes. Revista Contemporânea de Portugal e Brasil. Lisboa, tomo IV, ano 4, p. 329-353, abril de 1862. O mesmo ensaio acha-se reproduzido também no último dos quatro volumes da Obras de João Francisco de Lisboa, editadas em São Luís do Maranhão por Luís Carlos Pereira de Castro e Antônio Henriques Lea, em 1864 e 1865.

${ }^{16}$ Cf. Romero, op. cit., 1949. p. 35.

${ }^{17}$ Cf. Romero, op. cit., 1949. p. 35.
} 
Carlos Eduardo Gomesacima de tudo, um poeta que dignificaria qualquer língua". ${ }^{18}$ Segundo esse leitor, o tradutor produziu obra original de certo ponto de vista, porque põe à vista do leitor o tradutor e o traduzido sem trair nenhum dos dois. E ainda o aponta como sendo "dos poetas portugueses que possuem maior número de versos perfeitos". ${ }^{19}$ A questão está em que versos perfeitos não são suficientes para produzir poesia. $\mathrm{Na}$ verdade Aguiar não se mostra crítico muito exigente, considera Filinto Elísio poeta de cumeada e toma José Bonifácio como exemplo de poeta e, em momento algum, procede à análise dos poemas de Odorico a fim de partilhar com o leitor a fruição dos seus achados poéticos. Bonifácio deve ser lembrado por aquilo que é mais importante: a antecedência a Odorico na empreitada de helenização da língua portuguesa. Isso redunda na criação de novos vocábulos, tarefa em que o maranhense se extremará, como observa Candido na Formação da literatura brasileira e o leitor o confirmará na leitura dos poemas de Américo Elísio, nome arcádico de Bonifácio. Está ainda exposto como explicitação de um programa na nota introdutória que esse escreveu para sua tradução das Olimpicas de Píndaro:

Nós já temos muitos vocábulos compostos tirados do latim, e porque não faremos, e adotaremos muitos outros, tanto ou mais necessários em poesia, como por exemplo: auricómada, rocicómada, boquirubra, braccirósea, olhinegra, olhiamorosa, argentípede, tranciloira, docirisonha, docifalante, etc., etc.? Ousem mais os futuros engenhos brasileiros, agora que se abre nova época no vasto e nascente Império do Brasil à língua portuguesa, dar este nobre exemplo; e fico, que apesar de franzirem o beiço puristas acanhados, chegará o português, já belo e rico agora, a rivalizar em ardimento e concisão com a língua latina, de que traz a origem. $^{20}$

Assim como o professor cearense, também José Veríssimo foi bem mais condescendente que Romero e viu "fidelidade e concisão verdadeiramente assombrosa" 21 no trabalho do tradutor maranhense. Afirma ainda o autor da História da literatura brasileira que "A ciência das línguas clássicas, e da sua filologia e literatura, de que deixou prova

\footnotetext{
${ }^{18}$ Cf. Aguiar, M. Notas de português de Filinto e Odorico. Rio de Janeiro: Simões, 1955, p. 86.

${ }^{19}$ Cf. Aguiar, op. cit., p. 86.

${ }^{20}$ Cf. Bonifácio, J. Poesias de Américo Elísio. Obras de José Bonifácio de Andrada e Silva. Rio de Janeiro: Instituto Nacional do Livro, 1946. Vol. I, p. 72.

${ }^{21}$ Cf. Veríssimo, op. cit., p. 189.
} 
cabal e duas versões fidelíssimas, embora de custosa leitura, de Virgílio e de Homero, juntava estro poético original, se bem que escasso". ${ }^{22} \mathrm{E}$ mais ainda, "trasladou para o português os dois máximos poetas da Antiguidade clássica, não raras vezes aliás emulando-os em beleza e vigor de expressão". ${ }^{23}$ Como se vê, o severo crítico foi por demais generoso com o "Homero Brasileiro", como o chamaram Carvalho ${ }^{24} \mathrm{e}$ contemporâneos. Seria importante aqui destacar os adjetivos "original" e "escasso", referidos ao estro poético de Odorico, tanto quanto a emulação com os dois clássicos da Antiguidade.

Modernamente, críticos respeitáveis voltaram sua atenção ao trabalho de Manuel Odorico Mendes, como é o caso de Hélio Lopes, que lhe dedica páginas da sua tese de doutorado. ${ }^{25}$ Medina Rodrigues é outro que tem estudado extensamente o trabalho do tradutor maranhense, perscrutando-o em inúmeros trabalhos. Deve ser especialmente mencionado o nome de Sálvio Nienkötter, que organizou uma edição da Ilíada de Odorico, anotando-a verso a verso e completando com alentado prefácio. Mencione-se ainda o nome de Paulo Sérgio de Vasconcellos, que coordenou a preparação de esmerada edição bilíngue da Eneida brasileira, para a qual também contribuiu com uma introdução. Em 2008 circulou a edição bilíngue das Bucólicas, preparada e comentada pelo Grupo de Estudos Odorico Mendes, da Unicamp, enriquecida por estudos e comentários de cada poema. Por último é lembrado ainda o livro de Francisco Achcar, Lírica e lugar-comum, ${ }^{26}$ entre os que atentam a esse tradutor de Homero e Virgílio. ${ }^{27}$

Diz Haroldo de Campos que "Odorico Mendes é o patriarca da tradução criativa - da 'transcriação' - no Brasil”. ${ }^{28}$ Esse leitor propõe como visada mais adequada ao empreendimento desse tradutor aquela que caracteriza:

${ }^{22}$ Cf. Veríssimo, op. cit., p. 188.

${ }^{23}$ Cf. Veríssimo, op. cit., p. 189.

${ }^{24}$ Cf. de Carvalho, H. A. Ao leitor. In: Homero. Ilíada. Rio de Janeiro: Typographia Guttemberg, 1874, p. V.

${ }^{25}$ Cf. Lopes, op. cit.

${ }^{26}$ Cf. Achcar, F. Lírica e lugar-comum. São Paulo: Edusp, 1994.

${ }^{27}$ Esses, como os demais trabalhos referidos estão anotados nas Referências ao final deste estudo.

${ }^{28}$ Cf. de Campos, H. Odorico Mendes: o patriarca da transcriação. In: Homero. Odisseia. São Paulo: Edusp, 2000, p. 11. 
Como traço marcante de todo seu trabalho no campo, a concepção de um sistema coerente de procedimentos que lhe permitisse helenizar ou latinizar o português, em lugar de neutralizar a diferença dessas línguas originais, rasurando-lhes as arestas sintáticas e lexicais em nossa língua. ${ }^{29}$

À anotação de que Odorico, em seu empreendimento tradutório, propôs-se também à tarefa de helenizar e latinizar o português deve ser acrescido que procedeu a uma simultânea latinização da Grécia. Ao usar os nomes latinos para nomear o panteão grego, por exemplo, aparentemente procedeu esquecido de que a onomástica das divindades latinas não é uma sinonímia dos olímpicos. Esse procedimento terminou por significar uma espécie de desvalorização das duas culturas. O fato de esse procedimento ter nobres antecedentes - bastaria lembrar Camões, para não recuar à própria Roma Imperial - parece não tornálo legítimo, especialmente considerando-se que as circunstâncias do século 19 divergem absolutamente da época camoniana e da Antiguidade. O humanismo da Renascença, ao opor a Antiguidade à Idade Média, atribuiu àquela uma unidade que era perfeitamente aceitável do ponto de vista ideológico e histórico, pois se tratava de combater o que havia caducado na cultura da época apoiando-se no melhor da tradição clássica, opondo-a em bloco à era medieval, o que nada significava em pleno Romantismo brasileiro. Não havia um passado a ser recusado em sua totalidade, nem era possível ignorar a diferença entre as culturas antigas, especialmente numa era de diferenciação e afirmação das nacionalidades.

Essa tentativa de reduzir à unidade o que é em si tão diferente tem por consequência imediata uma permanente sensação de estranhamento causada ao leitor que é permanentemente chamado a ver Júpiter onde age Zeus; Juno em lugar de Hera, não bastasse a simples nominação de heróis como Odisseu pelo seu heterônimo latino. Tomese como exemplo o trecho famoso da Ilíada, que começa no verso 500 do primeiro canto, que é assim resumido pelo primeiro editor da tradução: "Entrevista de Tétis e de Júpiter consentindo em dar a vitória aos troianos. Queixas de Juno e ameaças de Júpiter em presença dos habitantes do Olimpo. Graças à intervenção de Vulcano, restabelece-se a paz na assembléia dos imortais". "É difícil a um leitor minimamente sensível reconhecer um abreviado dos versos homéricos nessa armadura virgiliana.

${ }^{29}$ Cf. de Campos, op. cit., 2000, p. 11.

${ }^{30}$ Cf. de Carvalho, op. cit., 1874, p. V. 
Odorico Mendes explica seu procedimento de tradutor como comprometido em:

Verter os epítetos com exatidão e nos lugares mais apropriados; isto feito, omito as repetições onde seriam enfadonhas. Ainda mais: vario a forma de cada epíteto, ou me sirvo de um equivalente: em vez de Aquiles velocípede, digo também impetuoso, rápido, fogoso; e assim nos demais. Note-se que os adjetivos gregos, terminando em casos diversos, não têm a monotonia dos nossos, que só variam nos dois gêneros e nos dois números. [...] Se vertermos servilmente as repetições de Homero, deixava a obra de ser aprazível como é a dele; a pior das infidelidades. Com isto não quero fazer a apologia das paráfrases: aspiro a ser tradutor. ${ }^{31}$

Como se percebe, não ambicionava pouco o ilustre maranhense. Reivindica a tradução adequada dos versos bem como a tarefa de suprir poeticamente as lacunas geradas pela transposição de uma à outra língua. Assim, talvez se possa registrar o nome de Manuel Odorico Mendes como um dos pioneiros na proposição de uma arte tradutória nas letras brasileiras.

Concisão é uma das palavras-chave na tentativa de se entender sua tradução. Usam-na o próprio tradutor, seu editor e também Lisboa, Veríssimo e leitores subsequentes. Trata-se, para Mendes, de mostrar a capacidade de concisão do português brasileiro, variante prolixa de uma língua prolixa. Assim, coerentemente, João Francisco Lisboa considera um feito merecedor de três pontos de exclamação o fato de ter o protoromântico maranhense, na tradução da Eneida, logrado a proeza de ter "9901 hexâmetros latinos convertidos em 9944 hendecassílabos portugueses!!!"32

Aparentemente as traduções de Odorico Mendes devem ser tomadas como parte do que Antonio Candido chamou "literatura empenhada". Para a sua geração tratava-se "do desejo de construir uma literatura como prova de que os brasileiros eram tão capazes quanto os europeus". ${ }^{33}$ Assim, entende-se a busca de emulação do tradutor com os clássicos, intentando superá-los no aspecto da sobriedade linguística, construindo versões mais curtas que as originais, realizando dessa forma

\footnotetext{
${ }^{31}$ Cf. Mendes, apud Homero. Ilíada. Tradução de Manuel Odorico Mendes. Rio de Janeiro: Typographia Guttemberg, 1874, p. 21.

${ }^{32}$ Cf. Lisboa, op. cit., 1874, p. XL.

${ }^{33}$ Cf. Candido, A. Formação da literatura brasileira. Momentos decisivos. Rio de Janeiro: Ouro Sobre Azul, 2007, p. 28.
} 
a proeza de superar as línguas clássicas, sintéticas, escrevendo em uma língua analítica. A edição de 1874 da Ilíada de Odorico abre com um quadro - "Quantos versos tem o original e quantos a tradução" - ${ }^{34}$ que, canto a canto, comparara o texto grego àquele de fatura do maranhense, mostrando o quanto este reduziu as dimensões do texto original. Ao pé da página, as totalizações: 15.674 e 13.116 , para o original e para a tradução, respectivamente.

Como anota Haroldo de Campos, Sousândrade chamou a Odorico Mendes "Pai Rococó". ${ }^{35}$ O Dicionário Aulete esclarece que o estilo rococó sucedeu ao barroco e caracterizava-se por apresentar uma "elegância afetada", e "pelo abuso das formas contornadas, labirínticas", podendo o termo ser usado figuradamente como sinônimo de "mau gosto; aparatoso mas destituído de ideal artístico" etc. Neste ponto interessa mais que o juízo estético, a condição de sucessão do barroco. Antonio Candido, por sua vez, fala de Odorico Mendes na sua Formação da literatura brasileira sob o título "Mau gosto", e observa que o ilustrado tradutor opera "alastrando a sua tradução da Ilíada de vocábulos e expressões que tocam as raias do bestialógico". E ainda: "Na poesia e nos sermões desse tempo, grassa, pois, um preciosismo do pior gosto, enfático, vazio, em que o termo raro, a imagem descabida, a construção arrevezada [sic] até à obscuridade são apoios duma inspiração pobre, em fase de decadência". ${ }^{36}$ Ora, essa descrição do crítico se encaixa exatamente ao rococó lembrado por Souzândrade - decadência de um barroco já de muito decadente, ao qual também Odorico Mendes remete o leitor, quando mais de uma vez consigna, em suas notas à tradução, que se serviu de versos de Dom Francisco Manuel de Melo, no labor tradutório. É este D. Francisco que em certo passo afirmou: "Não fiz livro em muitas horas para se ler em uma hora". ${ }^{37}$ Assim, talvez se possa atribuir à inspiração do Melodino ao menos uma parcela do arrevesamento sintático e morfológico que Antonio Candido identifica no tradutor e na sua geração literária.

Odorico Mendes traduziu sempre procedendo a um sistemático cotejo com outros tradutores homéricos às diversas línguas européias

\footnotetext{
${ }^{34} \mathrm{O}$ mesmo quadro existe também na versão de Odorico para a Odisseia, reproduzido na última página da edição de Medina Rodrigues.

${ }^{35}$ Cf. Souzândrade apud de Campos, H. Metalinguagem e outras metas. São Paulo: Perspectiva, 1992, p. 42.

${ }^{36}$ Cf. Candido, op. cit., p. 212.

${ }^{37}$ Cf. D. Francisco Manuel de Mello apud Spina, S. Introdução. In: de Mello, D. Francisco Manuel. A tuba de Calíope. São Paulo: Brasiliense/ Edusp, 1988, p. 18.
} 
(conduta assinalada também por José Bonifácio), avaliando criticamente as soluções escolhidas. Sem dúvida, procedimento altamente louvável como método tradutório. Porém, deve ser lembrado que o tradutor buscava muitas vezes, como já se disse, servir-se de termos usados por escritores consagrados. Aliás, não só palavras isoladas, mas versos inteiros eram interpolados nas suas traduções para os poemas de Homero. Tal como se serviu de D. Manuel de Melo, também o fez com Camões, Antônio Ferreira, Bocage e Filinto Elísio, enxertando-os no texto homérico, dando às suas traduções características de centões, como deixou meticulosamente consignado nas notas às traduções. Parece desnecessário comentar esse aspecto do seu empreendimento tradutório do ponto de vista da crítica literária.

\section{Em lugar de uma conclusão}

Desde Cícero - tradutor, do grego ao latim, dos discursos de Demócrito e Ésquines sobre a chamada "questão da coroa" - que afirmou não ter traduzido como um tradutor - ut interpres -, mas como verdadeiro orador - ut orator $^{38}$ - a abordagem da tradução literária pode ser abreviada (simplificadamente, é claro) a duas posições polares: elevar o leitor à obra literária, ou reduzi-la ao leitor. A primeira posição enriquecerá a língua de chegada ao confrontá-la com os procedimentos e modos linguísticos de outra língua; a segunda tornará a obra acessível a um público mais amplo, ao custo de empobrecê-la, ou, ao menos, expondo-se deliberadamente a esse risco.

Carlos Alberto Nunes é autor de outra tradução da Ilíada por demais conhecida e comentada que poderia ser cotejada à de Odorico, destacando-se o empenho do tradutor em preservar no português os ritmos poéticos do original. Assim, aproxima Homero do leitor moderno, ao mesmo tempo em que eleva este à poesia clássica, numa tentativa de servi-lo sem trair o poeta. De forma assemelhada procedeu o segundo, especialmente no que toca à linguagem. Não se questiona a legitimidade do seu trabalho, o que deve ser considerado são as soluções poéticas ou o quanto há de poesia na sua tradução. No procedimento desses dois tradutores pode o leitor mais facilmente visualizar as consequências práticas da tomada de posição pelo tradutor. Anote-se que contrapor a

${ }^{38}$ Cf. Cicéron. De optimo genere oratorum. In: . Cicéron, Brutus et la perfection oratoire. Traduction et organisation de Francis Richard. Paris: Garnier Frères, 1934, p. 229-243. 
tradução de Nunes à de Odorico não significa em nenhum momento ignorar o valor literário do seu trabalho, de que devem ser destacados pelo menos dois aspectos: o primeiro deles, uma certa contiguidade com a linguagem ordinária, evitando os contorcionismos e invenções linguísticas; e o segundo, o referido empenho na preservação do ritmo do poema homérico, enriquecendo dessa maneira a poética da nossa língua, ao recuperar as medidas clássicas para a nossa modernidade literária.

É visível e louvável o empenho de Odorico Mendes no sentido de elevar seu leitor à poesia imortal, não obstante os seus complicados torneios verbais, que tantas vezes destroem o ritmo, indispensável à poesia, como lembra a tradução de Nunes. O problema da sua tradução não reside aí. Criticá-la pela ilegibilidade apenas seria reduzir a discussão sobre a tradução à mera filologia, o que em nada contribui ao avanço do tema. Veja-se o que diz Haroldo de Campos que o apresenta aos seus leitores como "um pioneiro da tradução criativa, resgatado ao passado e ao descaso da crítica e reivindicado do ponto de vista de uma "poética sincrônica', afinada com o presente." ${ }^{39}$ Atribui-lhe nobre ascendência, nos "tradutores italianos de Homero - Monti e Pindemonte" ${ }^{40}$ e omite Américo Elísio, e, por trás deste, ao outro Elísio, o Filinto. Porém, anota ser "óbvio que sua prática não está à altura de sua teoria, que muitas de suas soluções, de seus arrevesamentos sintáticos e, em especial, de seus compósitos, são mesmo sesquipedais e inaceitáveis." ${ }^{41}$ Ou seja, a proposta de resgatá-lo do passado não impede Campos de reconhecer que a crítica de Candido, de que defende Odorico, é na verdade suave face ao que ele próprio tem a dizer do tradutor romântico. Na realidade, a resistência ao trabalho do maranhense será melhor compreendida quando - fazendo justiça a esses dois leitores tão aparelhados criticamente - for debitada à fraqueza poética do seu trabalho. Odorico foi um versejador menor, de pouco engenho; o talento de linguista e as breves e agudas reflexões do ensaísta não foram suficientes para salvar o poeta. Isto posto, deve ser dito que seu papel na literatura brasileira não pode ser obliterado, pelo seu pioneirismo, pelo seu comprometimento com esta literatura que ajudou a criar, tanto quanto por aqueles que entre os seus versos - sejam de circunstância, da sua lírica pessoal ou das traduções clássicas - mereçam ainda hoje ser lidos.

\footnotetext{
${ }^{39}$ Cf. de Campos, op. cit., 1992, p. 13.

${ }^{40}$ Cf. de Campos, op. cit., 1992, p. 39.

${ }^{41}$ Cf. de Campos, op. cit., 1992, p. 39.
} 


\section{Referências}

ACHCAR, F. Lírica e lugar comum. São Paulo: Edusp, 1994.

AGUIAR, M. Notas de português de Filinto e Odorico. Rio de Janeiro: Simões, 1955.

BONIFÁCIO, J. Poesias de Américo Elísio. Obras de José Bonifácio de Andrada e Silva. Rio de Janeiro: Instituto Nacional do Livro, 1946. Vol. I.

CAMPOS, Humberto de. Odorico Mendes: o patriarca da transcriação. In: HOMERO. Odisseia. São Paulo: Edusp, 2000. p. 9-14.

CAMPOS, H. de. Metalinguagem e outras metas. São Paulo: Perspectiva, 1992.

CAMPOS, H. de. Palavras necessárias. In: HOMERO. Odisseia. São Paulo: Edusp, 2000. p. 57-63.

CANDIDO, A. Formação da literatura brasileira. Momentos decisivos. Rio de Janeiro: Ouro sobre Azul, 2007.

CARVALHO, H. A. de. Ao leitor. In: HOMERO. Ilíada. Rio de Janeiro: Typographia Guttemberg, 1874, p. III-VIII.

CICERÓN. De optimo genere oratorum. In: . Cicéron, Brutus et la perfection oratoire. Traduction et organisation de Francis Richard. Paris: Garnier Frères, 1934, p. 229-243.

HOMERO. Ilíada. Trad. Manuel Odorico Mendes. Rio de Janeiro: Typographia Guttemberg, 1874.

HOMERO. Ilíada. Trad. Carlos Alberto Nunes. São Paulo: Melhoramentos, 1960.

LEAL, A. H. Manuel Odorico Mendes. In: Pantheon maranhense. Ensaios biográficos dos maranhenses ilustres já falecidos. Lisboa: Imprensa Nacional, 1873-1875. Vol. I, p. 1-99.

LISBOA, J. F. Biographia do auctor escripta e publicada em 1862 por João Francisco Lisboa. In: HOMERO. Iliada. Rio de Janeiro: Typographia Guttemberg, 1874, p. IX-XL.

LOPES, H. A divisão das águas. São Paulo: Conselho Estadual de Artes e Ciências Humanas, 1978.

de MELLO, D. Francisco Manuel. A tuba de Calíope. São Paulo: Brasiliense/ Edusp, 1988.

NIENKÖTTER, S. Apresentação/prefácio e anotações verso a verso. In: HOMERO. Ilíada. Trad. Manuel Odorico Mendes. Campinas: UNICAMP, 2008, p. 9-10/11-36 e mais de 300 p. para as anotações.

RODRIGUES, A. M. Apresentação/ Prefácio. In: HOMERO. Ilíada. São Paulo: Edusp, 2000, p. 15-18/19-54.

ROMERO, S. História da literatura brasileira. Rio de Janeiro: José Olympio, 1949. Vol. III. 
VASCONCELLOS, P. S. de. Apresentação/ introdução à "Eneida" de Odorico Mendes. In: MENDES, M. O. (tradutor). Eneida brasileira: ou tradução poética da epopeia de Públio Virgílio Maro por Manuel Odorico Mendes da cidade de S. Luís do Maranhão. Edição bilíngue. Campinas: UNICAMP, 2008, p. 7-8/9-18.

VERÍSSIMO, J. História da literatura brasileira. Brasília: UNB, 1963.

WOLF, F. Le Brésil littéraire. Histoire de la littérature brésilienne suivie d'un choix de morceaux tirés des meilleurs auteurs brésiliens. Berlin: A. Asher \& Co. (Albert Cohn \& D. Collin), 1863. 